ORIGINAL ARTICLE

\title{
Varicella vaccination in England and Wales: cost-utility analysis
}

\section{Brisson, W J Edmunds}

See end of article for authors' affiliations

.....................

Correspondence to: Dr W J Edmunds, PHLS Communicable Disease Surveillance Centre, 61

Colindale Avenue, London NW9 5EQ, UK;

jedmunds@hpa.org.uk

Accepted

3 January 2003

\begin{abstract}
Aims: To assess the cost-effectiveness of varicella vaccination, taking into account its impact on zoster. Methods: An age structured transmission dynamic model was used to predict the future incidence of varicella and zoster. Data from national and sentinel surveillance systems were used to estimate age specific physician consultation, hospitalisation, and mortality rates. Unit costs, taken from standard sources, were applied to the predicted health outcomes.

Results: In England and Wales, the annual burden of VZV related disease is substantial, with an estimated 651000 cases of varicella and 189000 cases of zoster, resulting in approximately 18000 QALYs lost. The model predicts that although the overall burden of varicella will significantly be reduced following mass infant vaccination, these benefits will be offset by a significant rise in zoster morbidity. Under base case assumptions, infant vaccination is estimated to produce an overall loss of 54000 discounted QALYs over 80 years and to result in a net cost from the health provider (NHS) and the societal perspectives. These results rest heavily on the impact of vaccination on zoster. Adolescent vaccination is estimated to cost approximately $£ 18000$ per QALY gained from the NHS perspective. Conclusion: Routine infant varicella vaccination is unlikely to be cost-effective and may produce an increase in overall morbidity. Adolescent vaccination is the safest and most cost-effective strategy, but has the least overall impact on varicella.
\end{abstract}

\section{METHODS}

\section{Model and methodological assumptions}

We compare three different vaccination strategies to no vaccination. The strategies are:

(1) Infant strategy: routine mass infant vaccination at $90 \%$ coverage.

(2) Catch-up strategy: infant strategy with catch-up (at $80 \%$ coverage) targeted at susceptible $2-11$ year olds in the first year.

(3) Adolescent strategy: routine vaccination of 11 year old susceptibles (at $80 \%$ coverage).

We used a realistic age structured (RAS) transmission dynamic model to predict the impact of vaccination on varicella and zoster. ${ }^{10}$ The average period of boosting following exposure to VZV was taken from Brisson and colleagues, ${ }^{9}$ and all other epidemiological parameter values were taken from
Brisson and colleagues ${ }^{11}$ unless otherwise stated. The model can capture herd immunity effects, including postimmunisation shifts in the age at infection.

We performed the economic analysis from the perspective of the health care provider (NHS) and of society. The primary viewpoint is that of the health care provider because data from this perspective are more complete for the UK. This perspective includes all direct medical costs including physician contacts, hospitalisations, and prescription medications. The societal perspective includes all medical and work loss costs as well as household expenditures. Future costs and outcomes are discounted at 3\% per year. In the sensitivity analysis, results are presented using alternative discount rates. Costs and benefits are presented over an 80 year time horizon. We chose cost and cost-utility analysis (cost per quality adjusted life year (QALY) saved) as analytical techniques.

\section{Vaccine efficacy and epidemiological estimates}

We estimated vaccine efficacy parameters values by fitting the predicted number of breakthrough infections (cases in seroconverted vaccinees) with observed data in clinical trials. ${ }^{10}$ The base, best, and worst case vaccine efficacy parameter values are presented in Brisson and colleagues. ${ }^{10}$

We estimated the predicted number of cases of natural and breakthrough varicella, and zoster directly from the model. The estimated age specific proportion of physician consultations, hospital length of stay, and deaths per case of varicella and zoster were applied to the predicted number of cases by age and time.

The age specific number of episodes of varicella and zoster which result in a consultation with a general practitioner (GP) and the average (age specific) number of consultations per episode were taken from the Royal College of General Practitioners (RCGP) Weekly Returns Service data for 1991-2000. ${ }^{12}$

Abbreviations: GP, general practitioner; QALY, quality adjusted life year; VZV, varicella zoster virus; VZIG, varicella zoster immunoglobulin 
Table 1 Health outcome estimates

\begin{tabular}{|c|c|c|c|c|c|c|c|}
\hline Parameters & All & $0-4$ & $5-14$ & $15-44$ & $45-64$ & $65+$ & Source* \\
\hline \multicolumn{8}{|l|}{$\%$ cases consult GP } \\
\hline Natural varicella & & $45 \%$ & $45 \%$ & $72 \%$ & $82 \%$ & $100 \%$ & [12] \\
\hline Breakthrough varicella & & $45 \%$ & $45 \%$ & $72 \%$ & $82 \%$ & $100 \%$ & {$[12,13]$} \\
\hline Zoster & & $100 \%$ & $100 \%$ & $100 \%$ & $100 \%$ & $100 \%$ & [12] \\
\hline \multicolumn{8}{|c|}{ Number of visits per consultation } \\
\hline Natural varicella & & 1.18 & 1.24 & 1.29 & 1.40 & 1.43 & [12] \\
\hline Breakthrough varicella & & 1.00 & 1.00 & 1.00 & 1.00 & 1.00 & Assumption \\
\hline Zoster & & 1.07 & 1.18 & 1.36 & 1.43 & 1.68 & {$[12]$} \\
\hline \multicolumn{8}{|l|}{ Hospitalisations per case } \\
\hline Natural varicella & & $0.37 \%$ & $0.14 \%$ & $0.62 \%$ & $1.38 \%$ & $3.14 \%$ & [12] \\
\hline Breakthrough varicella & & $0.07 \%$ & $0.03 \%$ & $0.12 \%$ & $0.28 \%$ & $0.63 \%$ & {$[12,14]$} \\
\hline Zoster & & $1.12 \%$ & $0.66 \%$ & $0.50 \%$ & $0.60 \%$ & $2.28 \%$ & [12] \\
\hline \multicolumn{8}{|l|}{ Length of stay } \\
\hline Natural varicella & & 2.22 & 2.96 & 3.97 & 5.77 & 10.57 & [12] \\
\hline Breakthrough varicella & & 2.22 & 2.96 & 3.97 & 5.77 & 10.57 & {$[12]$} \\
\hline Zoster & & 3.53 & 3.35 & 4.58 & 5.23 & 13.54 & [12] \\
\hline \multicolumn{8}{|l|}{ Case fatality } \\
\hline Natural varicella & & $0.001 \%$ & $0.001 \%$ & $0.009 \%$ & $0.073 \%$ & $0.689 \%$ & [12] \\
\hline Zoster & & $0.000 \%$ & $0.001 \%$ & $0.002 \%$ & $0.002 \%$ & $0.061 \%$ & [12] \\
\hline VZIG per case & & $0.2 \%$ & $0.2 \%$ & $3.3 \%$ & $0.2 \%$ & $0.2 \%$ & PHLS \\
\hline PHN per zoster case & & $0 \%$ & $1 \%$ & $4 \%$ & $11 \%$ & $31 \%$ & [17] \\
\hline Duration of PHN (days) & 511 & & & & & & [17] \\
\hline \multicolumn{8}{|l|}{ QALY lost per case } \\
\hline Natural varicella & & 0.004 & 0.004 & 0.005 & 0.005 & 0.005 & See methods \\
\hline Breakthrough varicella & & 0.001 & 0.001 & 0.001 & 0.001 & 0.001 & Assumption \\
\hline Zoster & 0.010 & & & & & & [17] \\
\hline PHN & 0.462 & & & & & & [17] \\
\hline
\end{tabular}

Age specific hospitalisation rates and length of stay data were taken from the Hospital Episodes Statistics (HES, Department of Health) for 1995-96, which covers the whole of England (numbers were multiplied up by the additional population size to include Wales). ${ }^{12}$ Based on Office of National Statistics (ONS) death certificates, the average number of deaths in England and Wales attributed to chickenpox and herpes zoster over the period 1993-2000 were used to calculate age specific case fatality ratios. ${ }^{12}$

Breakthrough cases were assumed to visit a physician at the same rate as natural varicella cases,$^{13}$ to have a fivefold lower risk of hospitalisation, ${ }^{14}$ and not to result in death. We excluded adverse events from our analysis since they are rare, ${ }^{15}$ and thus would not contribute significantly to the overall burden of the vaccine.

The age specific population size was taken from the Office for National Statistics (ONS) estimates for mid-1998. ${ }^{16}$ We used the population distribution of mid-1998 and assumed that the birth and death rates will remain constant in the future.

\section{Outcome measures}

Table 1 presents the QALYs lost due to varicella and zoster. QALYs lost due to zoster were taken from Edmunds and colleagues. ${ }^{17}$ To estimate the QALY lost due to varicella in children, parents were recruited from health clinics in London at the time of routine infant and child check-ups. Parents were approached in the waiting room where they were given an information leaflet and asked to participate in the study. Those consenting were asked to rate the health state of a child with chickenpox using an existing generic health status index (Health Utilities Index mark 2, HUI2). Only parents of children with prior history of chickenpox $(n=42)$ are reported in this study (further details of the study will be published elsewhere). The HUI2 was chosen because it was developed for childhood diseases using parents as proxies. The quality of life weighting of adults with chickenpox was assumed to be similar to that of mild zoster. To assess QALYs lost, varicella was assumed to have an average duration of seven days. An extensive sensitivity analysis was performed for these estimates.

\section{Cost data and assumptions}

Unit costs are in Sterling equivalent in $2001(£ 1=$ US\$1.5 or $€ 1.5$ ) and shown in table 2. Costs estimated in previous years are inflated to 2001 values by the use of the Hospital and Community Health Services (HCHS) Pay and Prices Index. ${ }^{18}$

\section{Direct costs}

The average cost per inpatient day and the average cost per GP consultation were taken from Unit Costs of Health and Social Care. ${ }^{19}$ Varicella zoster immunoglobulin (VZIG) in England and Wales is administered by the Public Health Laboratory Service (PHLS). Data from 2000 were used to estimate the average number of VZIG doses administered annually: 5426. Pregnant women given VZIG (4l66 vials) were assumed to be aged 15-44 years. Each vial of VZIG costs $£ 240$.

Wreghitt et al estimated the cost of infection control measures for a sample of 70 hospitalised patients with either varicella or zoster. ${ }^{20}$ Measures included serological diagnosis, staff exclusion, the use of VZIG and antiviral drugs, and patient isolation. We assume that these measures result in an average fixed cost associated with each hospitalised patient (that is, independent of their length of stay). Excluding the cost of administration of VZIG (to avoid double counting) this amounts to $£ 722$ per varicella hospitalisation, two thirds of which is due to staff exclusion. In all analyses it is assumed that contact with a breakthrough case by an at-risk susceptible would be as likely to result in the use of VZIG as contact with natural varicella.

The 1998 Prescription Cost Analysis for England ${ }^{21}$ was used to estimate the cost of community prescribed drugs for treatment of varicella and zoster (the cost of hospital prescriptions being included in the study by Wreghitt and colleague ${ }^{20}$ ) using assumptions described by Edmunds and colleagues. ${ }^{17}$ The average prescription cost per consultation for varicella and zoster is estimated to be $£ 2$ and $£ 35$ respectively.

In our base case analysis, we assumed the vaccine costs $£ 30$ per course (varied in the sensitivity analysis). For the infant strategy, we assume that varicella vaccination will be administered concurrently with MMR at 12-15 months, and therefore will not incur additional costs such as practice nurse 
Table 2 Cost estimates $(£)$

\begin{tabular}{|c|c|c|c|c|c|}
\hline Parameters & All & $\begin{array}{l}\text { Natural } \\
\text { varicella }\end{array}$ & $\begin{array}{l}\text { Breakthrough } \\
\text { varicella }\end{array}$ & Zoster & Source* \\
\hline \multicolumn{6}{|l|}{ Vaccination costs } \\
\hline Cost of vaccine course & 30 & & & & Assumption \\
\hline Extra cost per course for adolescent and catch-up & 10 & & & & Assumption \\
\hline \multicolumn{6}{|l|}{ Self reported history of chickenpox } \\
\hline Sensitivity & $97 \%$ & & & & [3] \\
\hline Specificity & $70 \%$ & & & & [3] \\
\hline \multicolumn{6}{|l|}{ Direct costs } \\
\hline Cost GP consult & & 22 & 22 & 22 & [19] \\
\hline Treat cost GP consult & & 2 & - & 35 & [21] \\
\hline Cost inpatient day & & 219 & 219 & 219 & [19] \\
\hline Average treat cost hospitalisation & & 722 & 722 & 875 & [20] \\
\hline Cost per dose of VZIG & & 240 & & & PHLS† \\
\hline \multicolumn{6}{|l|}{ Indirect costs } \\
\hline \multicolumn{6}{|l|}{ Not hospitalised } \\
\hline \multicolumn{6}{|l|}{ Work days lost per case } \\
\hline 0-15 & & 0.6 & 0.6 & 10 & {$[3,5,23]$} \\
\hline $16+$ & & 5.7 & 5.7 & 10 & {$[2,3,5]$} \\
\hline \multicolumn{6}{|l|}{ Hospitalised } \\
\hline \multicolumn{6}{|l|}{ Work days lost } \\
\hline $0-4$ & & 3.17 & 3.17 & 5.04 & Assumption \\
\hline $5-14$ & & 4.22 & 4.22 & 4.79 & Assumption \\
\hline $15-44$ & & 5.67 & 5.67 & 6.54 & Assumption \\
\hline $45-64$ & & 8.24 & 8.24 & 7.47 & Assumption \\
\hline \multicolumn{6}{|l|}{ Cost of a work day lost } \\
\hline $0-15$ & 30 & & & & {$[25]$} \\
\hline $16-17$ & 15 & & & & {$[25]$} \\
\hline $18-20$ & 23 & & & & {$[25]$} \\
\hline $21-24$ & 32 & & & & {$[25]$} \\
\hline $25-29$ & 51 & & & & {$[25]$} \\
\hline $30-39$ & 61 & & & & {$[25]$} \\
\hline $40-49$ & 63 & & & & [25] \\
\hline $50-59$ & 52 & & & & {$[25]$} \\
\hline $60-64$ & 24 & & & & {$[25]$} \\
\hline \multicolumn{6}{|l|}{ Household expenditures } \\
\hline $0-15$ & & 15 & - & - & {$[2,24,26]$} \\
\hline $16+$ & & 35 & - & - & {$[2,24,26]$} \\
\hline
\end{tabular}

consultations. For the catch-up and the susceptible adolescent programmes, it is assumed that each susceptible that is targeted is vaccinated at an additional cost of $£ 10$ over that of an infant course to cover the cost of a practice nurse consultation $^{19}$ and extra administration costs. For the catch-up and adolescent strategies, only children with negative or uncertain history of varicella are vaccinated. In our base case scenario, the sensitivity and specificity of determining a person's varicella history at 11 years was estimated to be $97 \%$ and $70 \%$ respectively. ${ }^{3}$ This is varied in the sensitivity analysis.

\section{Indirect costs}

There are no published estimates of absenteeism caused by chickenpox in the UK, although estimates exist from other industrialised countries. ${ }^{23522-24}$ The average number of workdays lost per case of varicella that does not require hospitalisation was taken from the average value from studies conducted in European countries, ${ }^{3523}$ taking into account the proportion of parents who both work. For adults with varicella an estimate of 5.7 days off work was used..$^{235}$ Since there are no published estimates of absenteeism caused by zoster, the

Table 3 Current burden of varicella and zoster

\begin{tabular}{|c|c|c|c|c|}
\hline & \multicolumn{2}{|l|}{ Varicella } & \multicolumn{2}{|l|}{ Zoster } \\
\hline & Base & $(90 \% \mathrm{Crl})$ & Base & (90\% Crl) \\
\hline \multicolumn{5}{|l|}{ Health outcomes } \\
\hline Cases & 651000 & & 189000 & \\
\hline PHN cases & & & 26000 & (25000 to 27000$)$ \\
\hline GP visits & 384000 & $(308000$ to *) & 277000 & \\
\hline Hospitalisations & 2200 & (* to 2700$)$ & 2100 & $\left({ }^{*}\right.$ to 3500$)$ \\
\hline Deaths & 20 & (19 to 26$)$ & 37 & $(30$ to 48$)$ \\
\hline Life years lost & 900 & (800 to 1200$)$ & 400 & $(400$ to 600$)$ \\
\hline QALYs lost & 3500 & (1900 to 4700$)$ & 14400 & (12100 to 24000$)$ \\
\hline \multicolumn{5}{|l|}{ Costs $(£ \mathrm{~m})$} \\
\hline \multicolumn{5}{|l|}{ Varicella } \\
\hline GP visits and VZIG & 10 & (7 to 10$)$ & 16 & (14 to 18$)$ \\
\hline Hospitalisation & 3 & (3 to 4$)$ & 6 & $(7$ to 13$)$ \\
\hline Work loss and household expenditures & 41 & (31 to 60$)$ & 146 & (119 to 183 ) \\
\hline Total & 54 & (41 to 74 ) & 169 & (140 to 214 ) \\
\hline
\end{tabular}


Table 4 Eighty year discounted (3\%) varicella and zoster health outcomes and costs saved from the various immunisation options

\begin{tabular}{|c|c|c|c|c|c|c|}
\hline & \multicolumn{2}{|l|}{ Infant } & \multicolumn{2}{|c|}{ Catch-up } & \multicolumn{2}{|c|}{ Adolescent } \\
\hline & Base & $(90 \% \mathrm{Crl})$ & Base & $(90 \% \mathrm{Crl})$ & Base & $(90 \% \mathrm{Crl})$ \\
\hline \multicolumn{7}{|l|}{ Health outcomes avoided } \\
\hline \multicolumn{7}{|l|}{ Varicella } \\
\hline Cases (millions) & 14.6 & & 15.7 & & 1.9 & \\
\hline GP consultations (millions) & 8.0 & $(6.6$ to *) & 8.7 & $(7.1$ to *) & 1.5 & $(1.0$ to *) \\
\hline Hospitalisations (thousands) & 46.9 & (* to 58.6$)$ & 51.9 & (* to 65.3 ) & 10.5 & (* to 12.6 ) \\
\hline Deaths & 22 & $(-23$ to 126$)$ & 199 & (109 to 296 ) & 128 & (111 to 210 ) \\
\hline Life-years saved (thousands) & 14.2 & & 17.4 & & 7.4 & \\
\hline QALYs saved (thousands) & 80.2 & & 88.5 & & 18.6 & \\
\hline \multicolumn{7}{|l|}{ Zoster } \\
\hline Cases (millions) & -0.6 & & -0.7 & & -0.1 & \\
\hline GP consultations (millions) & -1.1 & & -1.3 & & -0.1 & \\
\hline Hospitalisations (thousands) & -15.5 & $(-31.1$ to *) & -18.4 & $(-37.5$ to *) & -1.5 & $(-2.9$ to *) \\
\hline Deaths & -444 & $(-550$ to -336$)$ & -526 & $(-650$ to -393$)$ & -41 & $(-51$ to -31$)$ \\
\hline Life-years saved (thousands) & -4.1 & & -4.9 & & -0.4 & \\
\hline QALYs saved (thousands) & -134.6 & & -145.7 & & -11.0 & \\
\hline \multicolumn{7}{|l|}{ Overall VZV disease } \\
\hline Life-years saved (thousands) & 10.0 & $(7.7$ to 16.0$)$ & 12.5 & (11.2 to 21.5$)$ & 7.0 & $(6.0$ to 11.3$)$ \\
\hline QALYs saved (thousands) & -54.4 & $(-155.6$ to -44.1$)$ & -67.2 & $(-186.9$ to -40.6$)$ & 7.6 & $(-1.0$ to 13.2$)$ \\
\hline \multicolumn{7}{|l|}{ Costs (£million) } \\
\hline Vaccine costs & 524 & (405 to 644$)$ & 698 & (557 to 863 ) & 183 & (138 to 240 ) \\
\hline \multicolumn{7}{|l|}{ Direct medical costs prevented } \\
\hline GP consultations & 134 & (88 to 146$)$ & 141 & (90 to 152$)$ & 30 & (17 to 31$)$ \\
\hline Hospitalisations & -5 & $(-72$ to -1$)$ & -10 & $(-84$ to -4$)$ & 10 & $(5$ to 13$)$ \\
\hline VZIG & 18 & & 23 & & 11 & \\
\hline Total NHS costs prevented & 147 & & 154 & & 52 & \\
\hline Work loss and household expenditures prevented & 111 & $(-83$ to 673$)$ & 271 & (11 to 849 ) & 293 & (201 to 355$)$ \\
\hline Total societal costs prevented & 258 & & 425 & & 344 & \\
\hline
\end{tabular}

number of days off work was assumed to be the average age specific duration of disease multiplied by the proportion of workdays in a week.
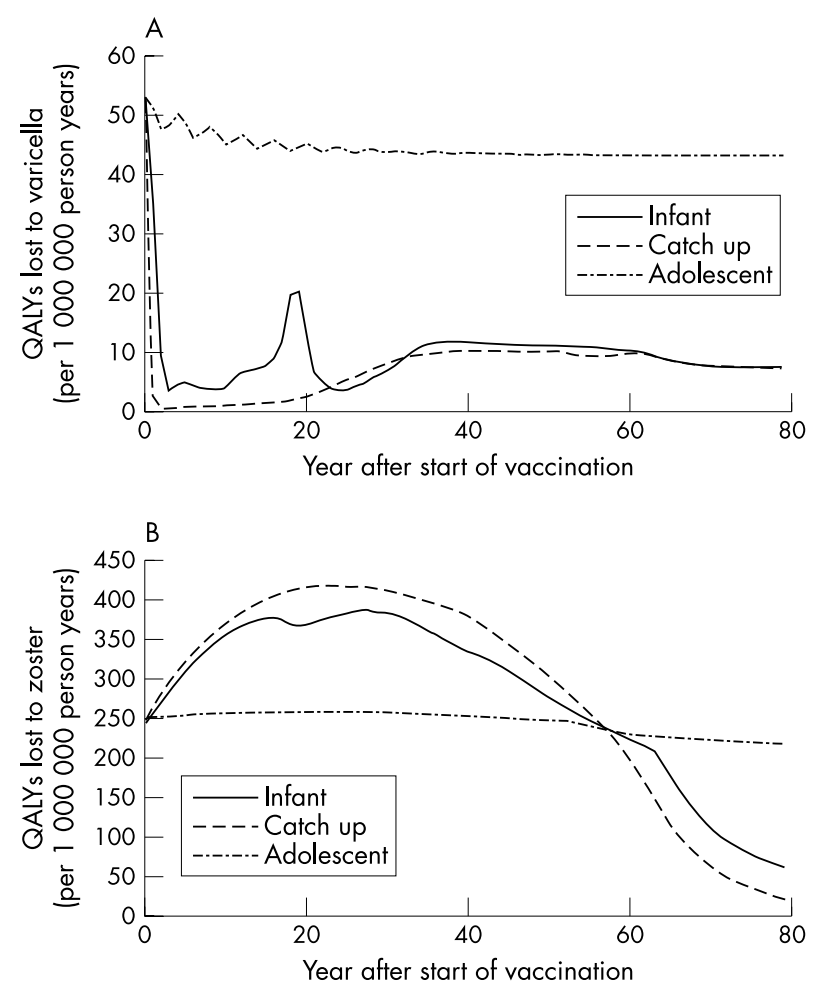

Figure 1 Estimated undiscounted QALYs lost due to $(\mathrm{A})$ varicella and (B) zoster over time following the introduction of vaccination (at year 0) for different vaccine strategies $(90 \%$ coverage, base case).
Work loss from hospitalised cases due to varicella and zoster was assumed to be twice the average age specific length of stay multiplied by the proportion of workdays in a week to take into account pre- and post-hospitalisation work loss.

To calculate the average cost of work loss arising from childhood cases of chickenpox and shingles, the average period of adult absence was multiplied by the average daily female wage in 25-34 year olds (weighted by the proportion in full and part time employment and inflated by rise in average earnings). ${ }^{25}$ For adult cases, the average period of absence was multiplied by the age specific average daily wage. It was assumed that there were no work loss costs caused by illness in those over 65 years of age. Household expenditures (for example, non-prescription medications and babysitting) were based on literature from North America, ${ }^{2426}$ since no published data exists for the UK.

\section{Sensitivity analysis}

The sensitivity of the results to variation in input parameters was explored by performing a probabilistic multivariate sensitivity analysis (uncertainty analysis). Input parameters were assigned probability distributions and combinations of these parameter values were drawn using Latin hypercube sampling, assuming that they are independent of each other. For each vaccination scenario, the model was run 1000 times to generate distributions of outcome variables using@risk version 4 (Palisade Corporation, New York) running within Microsoft Excel. The parameter values and the assumed input distributions are given in the appendix. All input distributions were assumed to be triangular. Results are presented with $90 \%$ credibility intervals $\left(C_{r} I\right)$, which show the 5th and 95th centiles of the outcome distributions. Univariate sensitivity analyses, in which parameters were varied one at a time, holding other parameter values at the base case level, were also performed. 
Table 5 Univariate sensitivity analysis to key parameters - health provider perspective

\begin{tabular}{|c|c|c|c|}
\hline & Infant & Catch-up & Adolescent \\
\hline Base case & QALY Loss* & QALY Loss & $£ 17673$ \\
\hline \multicolumn{4}{|c|}{ Vaccine and epidemiological parameters } \\
\hline Best case & QALY LOSS & QALY LOSS & $£ 24755$ \\
\hline Worst case & $£ 11327$ & $£ 10181$ & $£ 8172$ \\
\hline \multicolumn{4}{|l|}{ Vaccine coverage } \\
\hline $50 \%$ infants, $50 \%$ children & QALY LOSS & QALY LOSS & $£ 22841$ \\
\hline $95 \%$ infants, $90 \%$ children & QALY LOSS & QALY LOSS & $£ 16837$ \\
\hline \multicolumn{4}{|l|}{ Physician visits per case of varicella } \\
\hline Lower bound $90 \% \mathrm{Crl \dagger}$ & QALY LOSS & QALY LOSS & $£ 19566$ \\
\hline Upper bound $90 \% \mathrm{Crl} \dagger$ & QALY LOSS & QALY LOSS & $£ 17717$ \\
\hline \multicolumn{4}{|c|}{ Rate of hospitalisation and length of stay } \\
\hline Any ICD field & QALY LOSS & QALY LOSS & $£ 18021$ \\
\hline \multicolumn{4}{|l|}{ Summary outcomes } \\
\hline \multicolumn{4}{|l|}{ Case fatality ratio of varicella } \\
\hline Lower bound $90 \% \mathrm{Crl} \dagger$ & QALY LOSS & QALY LOSS & $£ 21126$ \\
\hline Upper bound 90\% Crl† & QALY LOSS & QALY LOSS & $£ 11129$ \\
\hline \multicolumn{4}{|l|}{ Case fatality ratio of zoster } \\
\hline Lower bound $90 \% \mathrm{Crl \dagger}$ & QALY LOSS & QALY LOSS & $£ 17454$ \\
\hline Upper bound $90 \% \mathrm{Crl} \dagger$ & QALY LOSS & QALY LOSS & $£ 17801$ \\
\hline \multicolumn{4}{|l|}{ QALY of varicella } \\
\hline Lower bound $90 \% \mathrm{Crl \dagger}$ & QALY LOSS & QALY LOSS & $£ 46323$ \\
\hline Upper bound 90\% CrI† & QALY LOSS & QALY LOSS & $£ 9582$ \\
\hline \multicolumn{4}{|l|}{ QALY of zoster } \\
\hline Lower bound $90 \% \mathrm{Crl} \dagger$ & QALY LOSS & QALY LOSS & $£ 12630$ \\
\hline Upper bound 90\% Crl† & QALY LOSS & QALY LOSS & QALY LOSS \\
\hline \multicolumn{4}{|l|}{ Costs } \\
\hline \multicolumn{4}{|l|}{ Cost per vaccine course } \\
\hline$-25 \%$ base case & QALY LOSS & QALY LOSS & $£ 13081$ \\
\hline$+25 \%$ base case & QALY LOSS & QALY LOSS & $£ 22266$ \\
\hline \multicolumn{4}{|l|}{ Cost per consultation } \\
\hline$-25 \%$ base case & QALY LOSS & QALY LOSS & $£ 18680$ \\
\hline$+25 \%$ base case & QALY LOSS & QALY LOSS & $£ 16667$ \\
\hline \multicolumn{4}{|l|}{ Cost per inpatient day } \\
\hline$-25 \%$ base case & QALY LOSS & QALY LOSS & $£ 18004$ \\
\hline$+25 \%$ base case & QALY LOSS & QALY LOSS & $£ 17306$ \\
\hline \multicolumn{4}{|l|}{ Prior history of varicella } \\
\hline \multicolumn{4}{|l|}{ Sensitivity } \\
\hline $90 \%$ & & QALY LOSS & $£ 19047$ \\
\hline $99 \%$ & & QALY LOSS & $£ 11048$ \\
\hline \multicolumn{4}{|l|}{ Specificity } \\
\hline $50 \%$ & & QALY LOSS & $£ 28058$ \\
\hline & & QALY LOSS & $£ 14463$ \\
\hline \multicolumn{4}{|c|}{ Model and methodological assumption } \\
\hline \multicolumn{4}{|c|}{ Duration of immunity to zoster after exposure to VZV } \\
\hline 7 years (lower bound $95 \% \mathrm{CI}$ ) & $£ 9396$ & $£ 10449$ & $£ 7679$ \\
\hline 11 years (lower bound $75 \% \mathrm{Cl}$ ) & QALY LOSS & QALY LOSS & $£ 11421$ \\
\hline 41 years (upper bound $95 \% \mathrm{Cl}$ ) & QALY LOSS & QALY LOSS & $£ 31258$ \\
\hline Discount rate & & & \\
\hline Benefits $6 \%$, costs $6 \%$ & QALY LOSS & QALY LOSS & $£ 74511$ \\
\hline Benefits $3 \%$, costs $6 \%$ & QALY LOSS & QALY LOSS & $£ 11049$ \\
\hline Benefits $0 \%$, costs $6 \%$ & $£ 6249$ & $£ 16933$ & $£ 1579$ \\
\hline Benefits $0 \%$, costs $3 \%$ & $£ 10214$ & $£ 23289$ & $£ 2521$ \\
\hline Benefits $0 \%$, costs $0 \%$ & $£ 19327$ & $£ 16511$ & $£ 5228$ \\
\hline Time scale & & & \\
\hline 30 years & QALY LOSS & QALY LOSS & $£ 29988$ \\
\hline
\end{tabular}

\section{RESULTS}

\section{Current burden of varicella and zoster}

The overall burden of VZV related disease is substantial (table $3)$. The predicted 651000 cases of varicella per year in England and Wales result in an estimated 384000 physician visits, 2200 hospitalisations, and 20 deaths. Comparatively, there are annually an estimated 189000 cases of zoster, and 277000 physician visits, 2100 hospitalisations, and 37 deaths. The estimated overall QALYs lost due to varicella and zoster is $18000\left(90 \% \mathrm{C}_{\mathrm{r}} \mathrm{I} 14000-29000\right), 80 \%$ of which are due to zoster.

The overall societal cost of VZV related disease in England and Wales is estimated to be $£ 223 \mathrm{~m}$ annually (90\% $\mathrm{C}_{\mathrm{I}} \mathrm{I}$, $£ 181 \mathrm{~m}-£ 288 \mathrm{~m}$; table 3$), 76 \%(£ 169 \mathrm{~m})$ of which are attributable to zoster. Most of societal costs $(£ 175 \mathrm{~m}, 78 \%)$ are due to work loss, $£ 12 \mathrm{~m}$ are due to household expenditures, and $£ 35 \mathrm{~m}$ are due to direct medical costs. Of the annual $£ 35 \mathrm{~m}$ VZV is estimated to cost the NHS, $£ 13 \mathrm{~m}$ is due to varicella ( $£ 20$ per case) and $£ 22 \mathrm{~m}$ is due to zoster ( $£ 116$ per case).

\section{Cost-utility analysis}

The model predicts that although the overall burden of varicella will significantly be reduced following mass infant vaccination, these benefits will be offset by a rise in zoster morbidity, which will last more than 60 years (see fig 1 and Brisson and colleagues ${ }^{11}$ ). Table 4 shows the predicted health outcomes prevented by vaccination. Under base case assumptions (90\% coverage and 3\% discount rate), infant vaccination would prevent $15 \mathrm{~m}$ varicella cases over 80 years and generate an extra $1 \mathrm{~m}$ cases of zoster, resulting in an overall loss of 


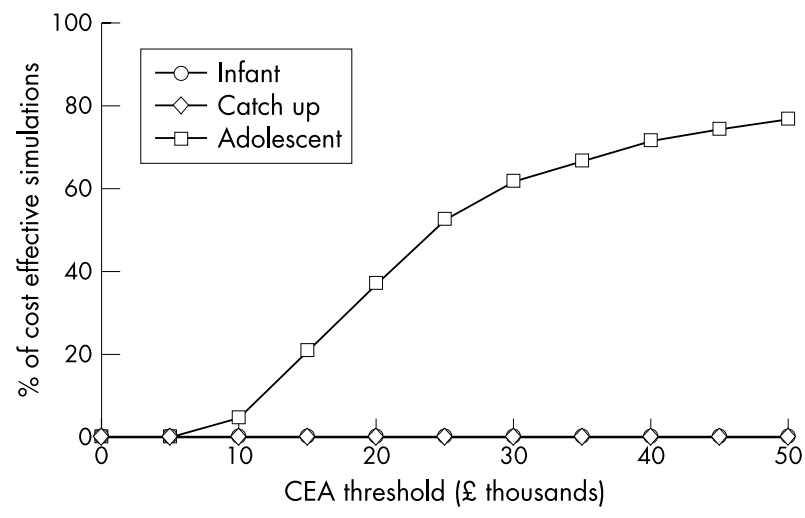

Figure 2 The proportion of simulations that would be deemed cost-effective for different threshold values of cost per QALY gained (vaccine efficacy and duration of immunity to zoster after exposure to VZV are held constant at base case values).

54000 discounted QALYs. The loss of QALYs is greater for the catch-up strategy (table 4) as the increase in zoster incidence is greater (fig 1). The projected discounted costs of the infant and catch-up programmes are $£ 524 \mathrm{~m}\left(90 \% \mathrm{C}_{\mathrm{r}} \mathrm{I}, £ 405 \mathrm{~m}-£ 644 \mathrm{~m}\right)$ and $£ 698 \mathrm{~m}\left(90 \% \mathrm{C}_{\mathrm{r}} \mathrm{I}, £ 557 \mathrm{~m}-£ 863 \mathrm{~m}\right)$ respectively, which is estimated to avoid $£ 147 \mathrm{~m}$ and $£ 154 \mathrm{~m}$ in direct medical costs (table 4). Thus, under base case assumptions, infant vaccination is estimated to produce an overall increase in morbidity (as measured by discounted QALYs) and to result in a net cost from the NHS perspective. Other catch-up strategies, such as vaccination of 11 year olds for the first 10 years of vaccination were investigated. Although less costly than the catch-up strategy presented here, such a strategy is estimated to result in a similar loss of QALYs.

Routine vaccination of 11 year olds (adolescent strategy) with $80 \%$ coverage reduces varicella cases by $2 \mathrm{~m}$ and results in zoster increases of less than $0.1 \mathrm{~m}$ over 80 discounted years (table 4), resulting in 8000 QALYs saved. This is estimated to result in savings of $£ 52 \mathrm{~m}$ in direct medical costs over 80 years, but at a cost of $£ 183 m\left(90 \% C_{r} \mathrm{I}, £ 138 m-£ 240 m\right)$ (table 4$)$. Thus, under base case assumptions, the cost-utility ratio for adolescent vaccination is estimated to be approximately $£ 18000$ per QALY gained.

Of the strategies investigated, only the adolescent strategy is cost saving from the societal perspective (present value of $161 \mathrm{~m}$ over 80 years; table 4 ). The infant and catch-up strategies are estimated to cost $£ 266 \mathrm{~m}$ and $£ 273 \mathrm{~m}$ over 80 discounted years respectively (table 4 ). The $90 \% \mathrm{C}_{\mathrm{r}} \mathrm{I}$ of these values are wide (table 4) since little is known of the indirect costs of zoster.

\section{Sensitivity analysis}

\section{Univariate sensitivity analysis}

Table 5 shows the sensitivity of results to changes in the key parameters. The cost-utility of infant and catch-up vaccination is most sensitive to vaccine efficacy and the duration of immunity to zoster after exposure to VZV. If vaccine efficacy is poor (worst case scenario) or duration of immunity to zoster after exposure to VZV is seven years (lower bound of the $95 \%$ CI estimated by Brisson and colleagues ${ }^{9}$ ), then infant and catch-up vaccination are estimated to cost approximately $£ 10000$ per QALY saved. The cost-effectiveness of infant varicella vaccination is also sensitive to the choice of discount rate and time frame of the analysis. Because zoster morbidity will eventually decline after 60 years, ${ }^{9-11}$ lower discount rates for benefits and longer time frames of analysis will cause varicella vaccination to be more cost-effective (table 5). Infant varicella vaccination remains highly cost-ineffective for changes in all other key parameters (table 5 ).
The results of the adolescent programme are sensitive to changes in parameter values. However, most scenarios cost less than $£ 25000$ per QALY saved. Parameters with the greatest impact on results are the QALYs lost due to varicella and zoster and the discount rate.

\section{Multivariate sensitivity analysis}

Figure 2 summarises the results of the multivariate (probabilistic) sensitivity analyses. Figure 2 can be interpreted as showing the probability that each of the programmes would be deemed cost-effective for alternative values of society's maximum willingness to pay for a QALY gained under base case assumptions regarding boosting following exposure to varicella. ${ }^{9}$ The results suggest that infant vaccination (with or without a catch-up programme) would be highly unlikely to be cost-effective. On the other hand, vaccination of susceptible 11 year olds is cost-effective under many acceptable criteria.

\section{DISCUSSION}

Conclusions regarding the cost-effectiveness of infant varicella vaccination (with and without catch-up) rest heavily on the impact it will have on the incidence of zoster. The increase in zoster following vaccination is dependent on vaccine effectiveness at preventing varicella and the length of time exposure to VZV protects against zoster. ${ }^{9-11}$ If duration of immunity to zoster after exposure to VZV is more than 10 years (lower bound of the $85 \% \mathrm{CI}^{9}$ ) and vaccination is effective at preventing varicella (as appears to be the $\operatorname{case}^{27}$ ), then universal infant strategies are unlikely to be cost-effective and are likely to produce an increase in overall morbidity (that is, losses of QALYs). This conclusion is robust to changes in all other key variables investigated here.

It should be noted that if time preference is such that short and long term benefits are valued equally (zero or very low discount rate), then infant varicella vaccination would be worthwhile, since after 60 years a reduction in zoster cases will occur, provided that vaccine recipients are less likely to develop zoster than individuals who have acquired natural infection..$^{9-11}$

Under all scenarios investigated, adolescent vaccination is the most cost-effective option from the health provider's perspective because, per vaccinee, there is a larger reduction of serious disease than for the infant programmes. Furthermore, it is the safest option since it has little effect on the age at infection and incidence of zoster. However, the cost-effectiveness of this strategy depends on the accuracy of the QALY measures for varicella and zoster.

\section{Strengths and limitations of the analysis}

The analysis presented here expands on previous analyses in three major areas. Most importantly we include the possible effect of zoster on the cost-effectiveness of varicella vaccination using a dynamic mathematical model ${ }^{11}$ parameterised from recent data. 'Secondly, we use cost per QALY as the main outcome measure. Using QALYs, instead of life-years gained, as most studies have done, ${ }^{1-6}$ is the more appropriate option since the main aim of varicella vaccination is to reduce VZV morbidity (VZV causes little mortality). Finally, like Lieu and colleagues, ${ }^{2}$ Coudeville and colleagues, ${ }^{5}$ and Brisson and Edmunds, ${ }^{6}$ we take into account herd immunity effects such as increases in the average age of varicella that would be expected to occur after vaccination.

The main limitation of the cost-effectiveness analysis presented here is the lack of data on the indirect costs due to varicella and zoster. Furthermore, the mathematical model has two main limitations. First, it has a simplified age structure in the elderly, which results in an underestimate of the overall burden of zoster in this age group. ${ }^{17}$ Hence, results may overestimate the cost-effectiveness of varicella vaccination. Finally, a better understanding of the mechanisms that 
lead to the development of shingles is needed to improve accuracy of model predictions.

At present there are no preventative measures against zoster. Vaccine trials are underway in the USA to determine whether immunisation of older adults will reduce the frequency and/or severity of zoster and post-herpetic neuralgia. If these are successful, then the optimal strategy may be to vaccinate both children and adults to prevent varicella and zoster, respectively.

\section{Conclusion}

Adolescent vaccination is the safest and most cost-effective strategy. Routine infant varicella vaccination is unlikely to be cost effective and may produce an increase in overall morbidity due to a rise in cases of zoster.

\section{APPENDIX}

Table Al presents input values for the multivariate analysis.

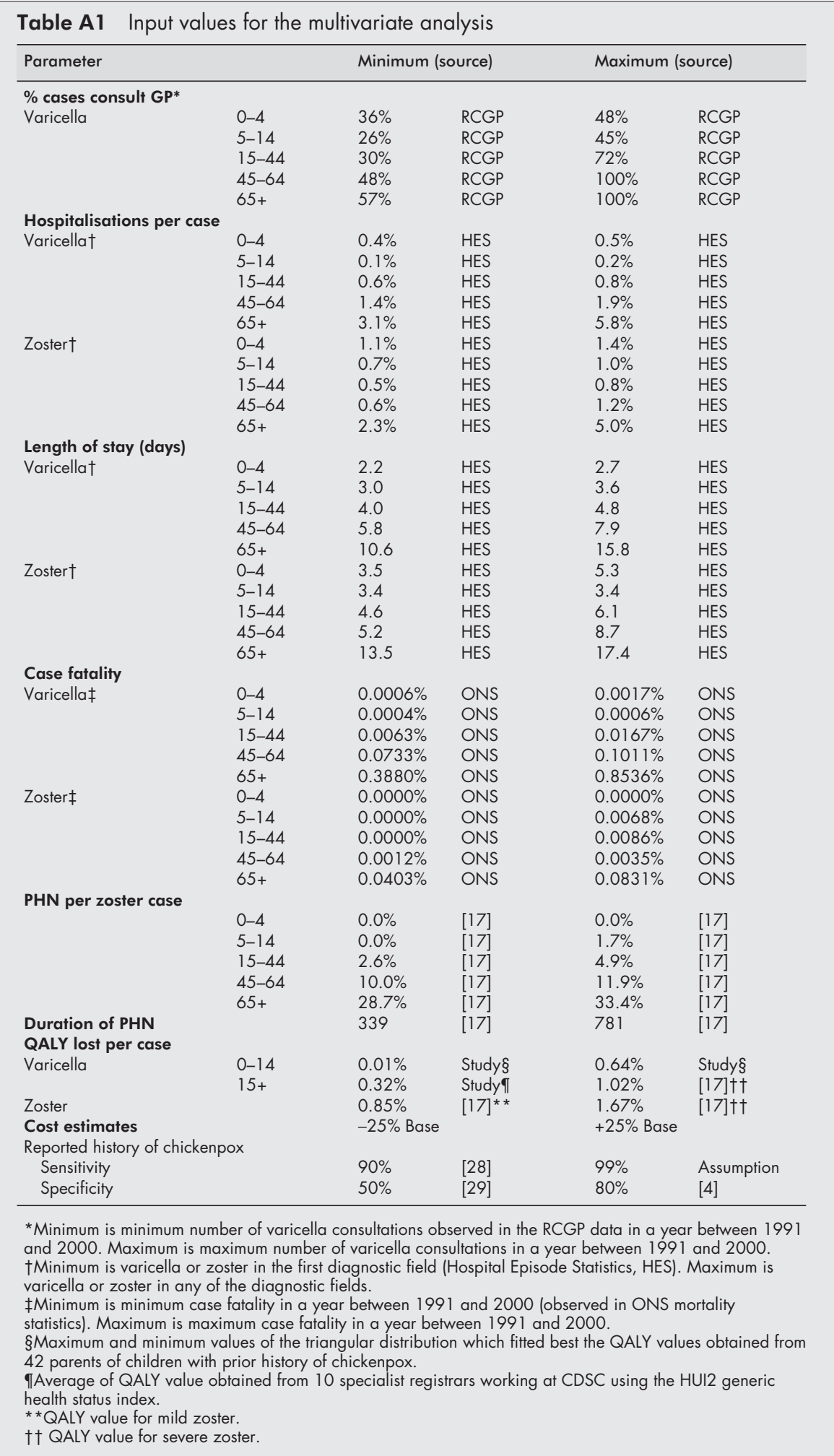




\section{ACKNOWLEDGEMENTS}

This study was funded by the UK Medical Research Council (grant number G9818303). We thank Dr Elizabeth Miller for comments on the manuscript, Teresa Gibbs for providing the VZIG data, and Pauline Kaye for providing the HES data. We would also like to thank the Office of National Statistics, and Dr Douglas Fleming and the Birmingham research unit, Royal College of General Practitioners, for data, and the anonymous referees for their thorough and very helpful comments.

\section{Authors' affiliations}

M Brisson, W J Edmunds, Immunisation Division, PHLS Communicable Disease Surveillance Centre, London NW9 5EQ, UK; Department of Economics, City University, London ECIV 3HD, UK

\section{REFERENCES}

1 Thiry N, Beutels $P$, Van Damme $P$, et al. Economic evaluations of varicella vaccination programmes: review of the literature. Pharmacoeconomics. 2003;21:13-38.

2 Lieu TA, Cochi SL, Black SB, et al. Cost-effectiveness of a routine varicella vaccination program for US children. JAMA 1994;271:37581.

3 Beutels P, Clara R, Tormans $G$, et al. Costs and benefits of routine varicella vaccination in Geman children. J Infect Dis 1996;174(suppl 3):S335-4 1

4 Scuffham PA, Lowin AV, Burgess MA. The cost-effectiveness of varicella vaccine programs for Australia. Vaccine 2000;18:407-15

5 Coudeville $L$, Paree $F$, Lebrun $T$, et al. The value of varicella vaccination in healthy children: cost-benefit analysis of the situation in France. Vaccine 1999;17:142-51.

6 Brisson M, Edmunds WJ. The cost-effectiveness of varicella zoster virus (VZV) vaccination in Canada. Vaccine 2002;20: $1113-25$.

7 Hope-Simpson RE. The nature of herpes zoster: a long-term study and a new hypothesis. Proc R Soc Med 1965;58:9-12.

8 Thomas SL, Wheeler JG, Hall AJ. Contacts with varicella or with children and protection against herpes zoster in adults: a case-control study. Lancet 2002;360:678-82.

9 Brisson M, Gay NJ, Edmunds WJ, et al. Exposure to varicella boosts immunity to herpes-zoster: implications for mass vaccination against chickenpox. Vaccine 2002;20:2500-7

10 Brisson M, Edmunds WJ, Gay NJ, et al. Modelling the impact of immunization on the epidemiology of varicella zoster virus. Epidemiol Infect 2000;125:651-9.
11 Brisson M Edmunds WJ, Gay NJ. Varicella vaccination: Impact of vaccine efficacy on the epidemiology of VZV. J Med Virol 2003;70:(suppl 1):S31-7.

12 Brisson M, Edmunds WJ. Epidemiology of varicella zoster virus in England and Wales. J Med Virol 2003;70(suppl 1):S9-14

13 Izurieta HS, Strebel PM, Blake PA. Postlicensure effectiveness of varicella vaccine during an outbreak in a child care center. JAMA 1997; 278: 1495-9.

14 Bernstein $\mathbf{H H}$, Rothstein EP, et al. Clinical survey of natural varicella compared with breakthrough varicella after immunization with live attenuated Oka/Merck varicella vaccine. Pediatrics 1993;92:833-7.

15 Wise RP, Salive Me, Braun MM, et al. Postlicensure safety surveillance for varicella vaccine. JAMA 2000;284:1271-9.

16 Office for National Statistics. Twentieth century mortality. CD-ROM. London: HMSO, 2000.

17 Edmunds WJ, Brisson M, Rose JD. The epidemiology of herpes zoster and potential cost-effectiveness of vaccination in England and Wales. Vaccine 2001; 19:3076-90.

18 NHS Executive. Health Service Cost Index. Appendix 1. NHS finance manual. London: Department of Health, 2001

19 Netten A, Curtis L. Unit costs of health and social care. Canterbury: PSSRU, 2001

20 Wreghitt TG Whipp J, Redpath C, et al. An analysis of infection control of varicella-zoster virus infection in Addenbrooke's Hospital Cambridge over a 5-year period, 1987-92. Epidemiol Infect 1996;117:165-71.

21 Department of Health Statistics Division. Prescription cost analysis 1998: England. London: HMSO, 1999: 165

22 Fornaro P, Gandini F, Marin M, et al. Epidemiology and cost analysis of varicella in Italy: results of a sentinel study in the pediatric practice. Pediatr Infect Dis J 1999;18:414-19.

23 Saddier P, Floret D, Guess HA, et al. Cost of varicella in France: a study in day care centers. J Infect Dis 1998; 178:S58-63.

24 Law B, Fitzsimon C, Ford-Jones L, et al. Cost of chickenpox in Canada: Part I. Cost of uncomplicated cases. Pediatrics 1999;104:1-6.

25 Office for National Statistics. New earnings survey. 1998.

26 De Wals P, Blackburn M, Guay M, et al. Burden of chickenpox on families: a study in Quebec. Can J Infect Dis 2001;12:27-32.

27 Seward JF, Watson BM, Peterson CL, et al. Varicella disease after introduction of varicella vaccine in the United States, 1995-2000. JAMA 2002;287:606-11.

28 Wallace MR, Chamberlin CJ, Zerboni L, et al. Reliability of a history of previous varicella infection in adults. JAMA 1997;278:1520-2.

29 Ronan K, Wallace MR. The utility of serologic testing for varicella in an adolescent population. Vaccine 2001;19:4700-2. 